\title{
The 8D05 Parasitism Gene of Meloidogyne incognita Is Required for Successful Infection of Host Roots
}

\author{
Bingye Xue, Noureddine Hamamouch, Chunying Li, Guozhong Huang, \\ Richard S. Hussey, Thomas J. Baum, and Eric L. Davis
}

First, third, and seventh authors: North Carolina State University, Department of Plant Pathology, Raleigh 27607; second author: Longwood University, Department of Biological \& Environmental Sciences, Farmville, VA 23909; fourth and fifth authors: University of Georgia, Center for Tropical and Emerging Global Diseases and Department of Plant Pathology, respectively, Athens 30602; and sixth author: Iowa State University, Department of Plant Pathology, Ames 50011.

Accepted for publication 9 October 2012.

\begin{abstract}
Xue, B., Hamamouch, N., Li, C., Huang, G., Hussey, R. S., Baum, T. J., and Davis, E. L. 2013. The 8D05 parasitism gene of Meloidogyne incognita is required for successful infection of host roots. Phytopathology 103:175-181.

Parasitism genes encode effector proteins that are secreted through the stylet of root-knot nematodes to dramatically modify selected plant cells into giant-cells for feeding. The Mi8D05 parasitism gene previously identified was confirmed to encode a novel protein of 382 amino acids that had only one database homolog identified on contig 2374 within the Meloidogyne hapla genome. Mi8D05 expression peaked in M. incognita parasitic second-stage juveniles within host roots and its encoded protein

secreted from the stylet. Constitutive expression of Mi8D05 in transformed Arabidopsis thaliana plants induced accelerated shoot growth and early flowering but had no visible effects on root growth. Independent lines of transgenic Arabidopsis that expressed a double-stranded RNA complementary to Mi8D05 in host-derived RNA interference (RNAi) tests had up to $90 \%$ reduction in infection by $M$. incognita compared with wild-type control plants, suggesting that Mi8D05 plays a critical role in parasitism by the root-knot nematode. Yeast two-hybrid experiments confirmed the specific interaction of the Mi8D05 protein with plant aquaporin tonoplast intrinsic protein 2 (TIP2) and provided evidence that the Mi8D05 effector may help regulate solute and water transport within giant-cells to promote the parasitic interaction.
\end{abstract} was limited to the subventral esophageal gland cells that produce proteins
The ability to infect the roots of over 1,700 different plant species has made the root-knot nematodes (Meloidogyne spp.) one of the most successful and devastating parasites of crops found worldwide $(5,11,48)$. Infective second-stage juveniles (J2) completely penetrate plant roots and migrate intercellularly to the root vascular tissue where they induce the formation of localized feeding sites called giant-cells from immature plant vascular cells (33). The giant-cells become the essential, permanent food source for the invading nematode as it assumes a sedentary lifestyle through growth and successive molts towards the pyroform reproductive adult stage. Morphological and molecular studies of giant-cell ontogeny suggest that root-knot nematodes manipulate fundamental plant cell biology to achieve the phenotype of giantcells in such a wide array of plant species $(1,4,20,21,34)$. The nematodes feed from giant-cells using the hollow, protrusible stylet in their head, and they also use the stylet to secrete effector proteins into plant cells to initiate and maintain the feeding site $(13,15,45)$. The secreted effector proteins are encoded by parasitism genes that are specifically and developmentally expressed in three large secretory gland cells within the nematode esophagus $(14,15,31)$. The two subventral esophageal gland cells are active mainly during root penetration and migration by the nematode, and become less active as the single dorsal gland cell grows in size and activity during feeding site initiation and maintenance throughout the parasitic cycle of the biotroph. Investigations to date have identified multiple parasitism genes in the

Corresponding author: E. L. Davis; E-mail address: eric_davis@ncsu.edu

http://dx.doi.org/10.1094/PHYTO-07-12-0173-R

(c) 2013 The American Phytopathological Society sedentary root-knot and cyst endoparasitic nematodes through analyses of developmentally expressed genes $(13,15,45)$ and secretome prediction from genomic analyses $(2,39)$.

Functional analyses of predicted effector molecules encoded by different phytoparasitic nematode parasitism genes have remained a challenge because the nematodes are microscopic biotrophs embedded within plant roots and they are currently not amenable to molecular transformation. The adoption of the model plant species Arabidopsis thaliana (50) for studies of parasitism gene function has, however, provided a wealth of technical and genetic resources on the host side of the plant-nematode interaction. Constitutive expression of individual nematode parasitism genes in transformed plant roots has been used for initial assessments of expressed effector effects on plant phenotype and susceptibility to nematode infection $(18,24,25,28,35,41,42,54,56)$. The utility of the RNA interference (RNAi) technology developed in Caenorhabditis elegans (19) has also provided a powerful tool to specifically silence target phytonematode parasitism genes (46) through assays that either soak infective $\mathrm{J} 2(3,10)$ in solutions of doublestranded RNA (dsRNA) or provide dsRNA complementary to target parasitism genes for nematode ingestion from within transgenic plants $(27,41,42,51)$. Yeast two-hybrid screens using single expressed parasitism proteins as baits and total root proteins (expressed from root cDNA libraries) as prey $(24,25,28,35$, $41,44)$ have begun to identify specific interactions between nematode effectors and host proteins that appear to manipulate different cellular processes in plants $(21,45)$.

Greater than 40 parasitism genes were identified in the rootknot nematode, Meloidogyne incognita, using esophageal gland cell microaspiration and transcript mining assays $(29,30)$. While a number of those root-knot nematode parasitism genes encoded effector proteins like cell wall-modifying enzymes and a few 
other database orthologs, approximately $70 \%$ of the $M$. incognita parasitism genes encoded novel effector proteins. The $8 D 05$ parasitism gene of $M$. incognita encodes one of those novel effector proteins and is somewhat unusual in that $8 D 05$ is expressed in the nematode's subventral esophageal gland cells through the entire life cycle (30). Analyses presented here suggest that 8D05 is critical for parasitic success of $M$. incognita and that it interacts specifically with host plant tonoplast intrinsic protein 2 (TIP2).

\section{MATERIALS AND METHODS}

Nematodes and infection assays. The root-knot nematode, $M$. incognita race 4, was propagated in the greenhouse on roots of soil-grown tomato plants (Solanum lycopersicum 'Rutgers') and $M$. incognita eggs were extracted from egg masses on root galls using $0.5 \%$ sodium hypochlorite as previously described (32). Nematode eggs were hatched over water at $28^{\circ} \mathrm{C}$ on Baermann pans for $48 \mathrm{~h}$ and the hatched preparasitic second-stage juveniles (pre-J2s) were collected for use in root infection assays or frozen at $-80^{\circ} \mathrm{C}$ for subsequent nucleic acid extractions. Mixed parasitic stages of $M$. incognita were collected for gene expression analysis from within roots of tomato plants by gentle root blending and sieving as described in Ding et al. (17). Intact $M$. incognita life stages extracted from tomato roots were separated into groups of parasitic J2 (para-J2), J3, J4, and adult female stages under a dissecting microscope and frozen at $-80^{\circ} \mathrm{C}$ for subsequent use in the quantitative real-time reverse-transcription polymerase chain reaction (qRT-PCR) experiments described below.

Arabidopsis thaliana ecotype Columbia (Col-0) was used as wild type to generate all transgenic plant lines described below and for infection assays with $M$. incognita. For nematode infection assays, all Arabidopsis seeds were surface sterilized with $10 \%$ sodium hypochlorite and $0.01 \%$ Tween 20 for $3 \mathrm{~min}$ followed by $1 \mathrm{~min}$ with $70 \%$ ethanol. Seeds were washed five times with sterile distilled water to remove residual sterilization solution. Five days after seed germination on MS medium (38), the Arabidopsis seedlings were transplanted into 3-inch plastic pots of soil (93.3\% sand, $3.3 \%$ silt, and $3.4 \%$ clay), one plant per pot. One week after transplanting, 1,000 freshly hatched J2 of $M$. incognita were added to the soil at the base of each Arabidopsis test plant. All treated plants were fertilized with liquid Knops medium (50) once a week in the first 2 weeks after transplanting. At 30 days postinoculation, root systems were gently washed in water, blotted dry to asses root fresh weight, and the number of galls on each root system was counted under a dissecting microscope. The mean and standard error of 20 replicates per treatment were calculated and statistical differences in mean $(n=$ 20) were determined by the paired $t$ test with an alpha level of 0.05 using SAS software (SAS Institute, Cary, NC).

Analyses of the $M$. incognita $8 D 05$ gene and protein. Genomic DNA was extracted from J2 of $M$. incognita as previously described (41). The genomic DNA sequence of Mi8D05 was obtained from the PCR product using the gene-specific primers 8D05-FL-F1 (5'-TAGTCAGTCATTTAAAATAATTTAAT-3') and 8D05-FL-R1 (5'-GTTTAATTCACTTTTTTCACATCAT-3'), which were designed on the cDNA sequence deposited in GenBank (AF531169). The full-length Mi8D05 genomic DNA sequence was used for nucleotide search of the genomes of M. hapla, Heterodera glycines, and $C$. elegans in NCBI. Software Vector NTI (Invitrogen, Grand Island, NY) was used to analyze the DNA and amino acid sequences. Predicted secretion signal peptide and protein structure were analyzed, respectively, by SignalP 3.0. (6) and SMART (49) software.

Polyclonal antiserum to Mi8D05 was produced by immunizing rabbits with synthetic peptides 8D05-1 (CYDDNEKADYGD LAAELAK) and 8D05-2 (CKRHGRPHRLNDWNNPFP) (Alpha Diagnostic Intl. Inc., San Antonio, TX). Peptide affinity-purified
8D05 polyclonal antisera were used to localize 8D05 expression within specimens of $M$. incognita using immunofluorescence microscopy (28).

Transgenic Arabidopsis that expressed $8 D 05$ and complementary RNAi. For overexpression in plants, the open reading frame (ORF) of parasitism gene Mi8D05 without signal peptide was amplified by primers 8D05-pBI-wosp-F1 (5'-CGGATCCAT GGTAACCGAGAATAAGAAT-3') and 8D05-pBI-wosp-R1 (5'GAGCTCTTAGTTGTGATAAAAATGGATTT- $\left.3^{\prime}\right)$. The PCR product was digested with BamH1 and $\mathrm{SacI}$ and then cloned into vector pBI121 (9) under the control of CaMV 35S promoter. The identity, orientation, and junctions of the resulting $35 S:: 8 D 05$ construct were confirmed by PCR and DNA sequencing.

To express hairpin dsRNA for in planta RNAi assays, the sense and antisense ORF sequences of $8 D 05$ were amplified by primers 8D05-RNAi-HindIII-Xho (5'-AAGCTTCTCGAGATGTTTTTAC AAAAAC-3'), which introduces sense into XhoI site and antisense into HindIII site, and 8D05-RNAi-Cla-Kpn (5'-ATCGA TGGTACCTTAGTTGTGATAAAAAT-3'), which introduces sense into KpnI site and antisense into ClaI site of pHANNIBAL (57) behind the CaMV $35 \mathrm{~S}$ promoter. The 8D05-RNAi construct made in pHANNIBAL was isolated by restriction digestion with NotI enzyme and cloned into the pART27 binary vector (22) for subsequent Agrobacterium and plant transformation, resulting in pART-8D05.

Plasmids pBI-8D05 and pART-8D05 were introduced into Agrobacterium tumefaciens $\mathrm{C} 58 \mathrm{C} 1$ by electroporation, verified by PCR, and transformed into Arabidopsis thaliana wild-type Col-0 plants by floral dip (12). Transgenic seeds were selected on MS media supplemented with kanamycin at $50 \mathrm{mg} /$ liter. Segregation analyses identified homozygous lines and the resultant homozygous plants were characterized for construct expression using RT-PCR. The homozygous transgenic lines were monitored for potential effects of pBI-8D05 and pART-8D05 expression on plant growth phenotype $(n=12)$ and also subjected to infection assays with $M$. incognita as described above.

Interaction of Mi8D05 with plant proteins. To identify potential plant proteins that could potentially interact with Mi8D05 within plant cells during infection, yeast two-hybrid screenings were performed as described in the BD Matchmaker Library Construction and Screening Kits user manual (Clontech Laboratories, Mountain View, CA). The cDNA encoding the mature peptide of Mi8D05 without signal peptide was cloned in-frame into the GAL4-binding domain of pGBKT7 by using primers containing EcoRI (5'-GAATTCGTAACCGAGAATAAGAATA$\left.3^{\prime}\right)$ and BamH1 (5'-GCGGATCCCATTCACTTTTTTCACATCAT $\mathrm{T}-3^{\prime}$ ) restriction sites, respectively to generate pGBKT7-8D05 and expressed as bait to screen tomato root cDNA prey libraries constructed in the GAL4 activation domain of the pGADT7-Rec vector. The root cDNA libraries were constructed from mRNAs extracted from noninfected tomato roots (28) and from tomato roots at 7 days after infection by $M$. incognita (to enhance for plant genes and products upregulated in feeding sites). Positive yeast two-hybrid matings were selected on a series of selective media as described in the protocol of the Matchmaker yeast twohybrid system and subjected to subsequent co-transformation of isolated clones to validate positive protein-protein interactions (25).

Quantitative analyses of gene expression. qRT-PCR was used to analyze the developmental expression of 8D05 within $M$. incognita and the gene encoding the tomato tonoplast intrinsic protein 2 (tip2; AY731066) that was confirmed to interact with Mi8D05 in yeast two-hybrid screens. Total RNA was extracted from $50 \mathrm{mg}$ each of nematode tissue from pre-J2, para-J2, J3, J4, and female $M$. incognita life stages using the RNAeasy Mini Kit (Qiagen, Valencia, CA). The RNAeasy Plant Mini Kit (Qiagen) was used to isolate total RNA from $100 \mathrm{mg}$ of frozen, ground tomato root tissue isolated at 5,14 , and 24 days after infection by 
M. incognita. For each sample, $150 \mathrm{ng}$ of DNase-treated RNA was used for cDNA synthesis and the cDNAs were generated by PCR amplification using SuperScript II Reverse Transcriptase (Invitrogen).

Gene-specific primers for 8D05 (AF531169), tip2 (AY731066), M. incognita actin (BE225475), and tomato actin (U60481) were designed for quantitative analyses. All qRT-PCR runs were performed in a DNA Engine Mx3000P instrument (Agilent Technologies, Santa Clara, CA). A single 20- $\mu$ l PCR reaction included $1 \times$ Brilliant II SYBR Green qPCR Master Mix (Agilent Technologies, Santa Clara, CA), $2 \mu$ of cDNA template, and $5 \mu \mathrm{M}$ each forward and reverse primers. The PCR cycling parameters were set at $95^{\circ} \mathrm{C}$ for $10 \mathrm{~min}$ followed by 40 cycles of $95^{\circ} \mathrm{C}$ for $30 \mathrm{~s}, 60^{\circ} \mathrm{C}$ for $30 \mathrm{~s}$, and $72^{\circ} \mathrm{C}$ for $45 \mathrm{~s}$. The dissociation melt curve analysis in which all products generated during the PCR amplification reaction were melted at $95^{\circ} \mathrm{C}$ for $1 \mathrm{~min}$, then annealed at $55^{\circ} \mathrm{C}$ for $30 \mathrm{~s}$, and subjected to gradual increases in temperature was conducted to discount the effects of primerdimer formation and contamination. The qRT-PCR reactions were performed in triplicate and the negative controls included water and mRNA extracted from the nematodes to check for DNA contamination in the analyzed samples. All qRT-PCR samples were normalized against the tomato actin gene (U60481) or the $M$. incognita nematode actin gene (BE225475) as appropriate. Three biological replicates (separate tissue samples) were analyzed per treatment and a composite result was derived for comparative analyses. The paired $t$ test with an alpha level of 0.05 was used to compare relative transcript level means from normalized qRT-PCR measurements using the statistical software package of SAS. The fold-change relative to control plants was calculated from normalized qRT-PCR measurements according to the $2^{-\Delta \Delta \mathrm{CT}}$ method (36).

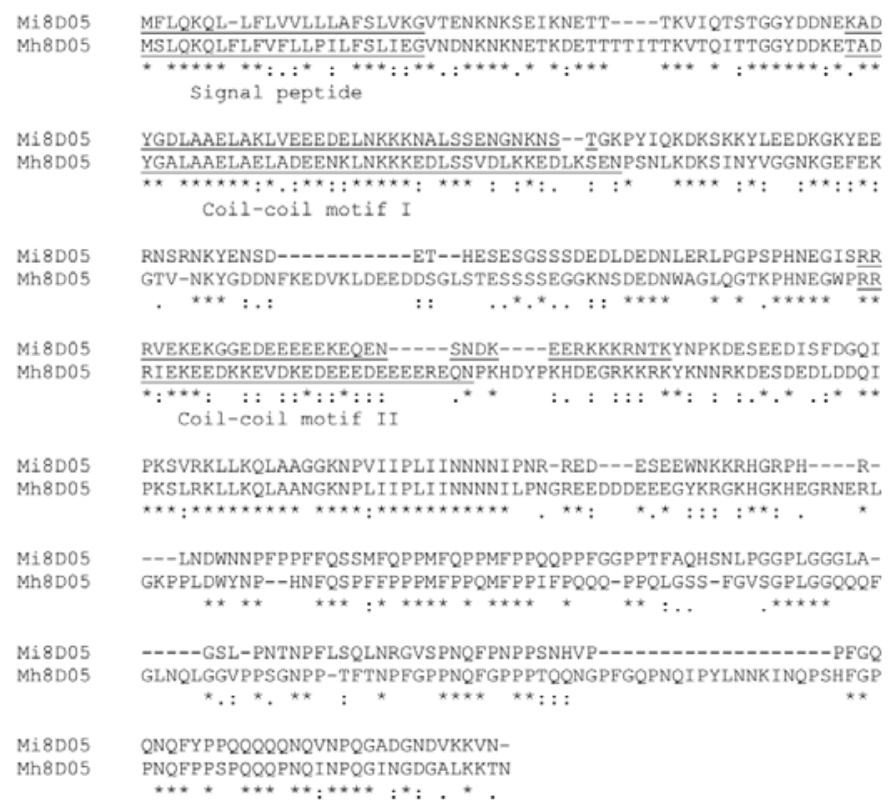

Fig. 1. Alignment of the predicted amino acid sequences derived using Vector NTI Suite (Invitrogen) from the nucleic acid sequence of the novel $8 D 05$ parasitism gene of the root-knot nematodes Meloidogyne incognita (Mi) and M. hapla (Mh). Included are amino acid sequences predicted from a 1,414-bp Mi8D05 genomic clone (HQ728271) and from a 1,602-bp Mh8D05 genomic DNA sequence identified on contig 2374 (ABLG01002375) of the M. hapla genome (39). A 55\% predicted amino acid similarity was observed between Mi8D05 and Mh8D05 and each had a secretion signal peptide (underlined) at the $\mathrm{N}$ terminus as predicted by SignalP (6). A conserved coil-coil motif predicted using SMART (49) was identified (underlined) at amino acids 53 to 90 and 159 to 194 of Mi8D05 and at amino acids 58 to 99 and 178 to 206 of Mh8D05.

\section{RESULTS}

Analyses of the Mi8D05 sequence, expression, and its encoded protein. Nucleotide sequence of the original Mi8D05 cDNA pGEM clone, 8D05 cDNA derived from mRNA expressed in $M$. incognita nematode specimens, and genomic sequence of Mi8D05 in these studies indicated that the original GenBank submission (AF531169) was missing a nucleotide at position 1179 resulting in a false frame-shift and truncation of the c-terminal region of the predicted protein. Thus, the Mi8D05 coding sequence identified in these studies was used for all corresponding assays and comparative analyses. The longest ORF of the Mi8D05 cDNA (1,149 bp) encoded a deduced protein (Fig. 1) of 382 amino acids (aa) that included a 22-aa N-terminal signal peptide as predicted by Signal P (6). A 1,414-bp genomic DNA fragment of Mi8D05 (HQ728271) was isolated by PCR using primers designed based on the cDNA sequence of Mi8D05 (AF531169). Analysis of the 1,414-bp sequence identified one intron of $163 \mathrm{bp}$ in the $5^{\prime}$-UTR but no intron sequences were identified within the predicted ORF.

BLAST of the 1,414-bp genomic sequence of Mi8D05 against the complete genome sequences of $M$. hapla, $H$. glycines, and $C$. elegans identified a 1,602-bp fragment (designated as Mh8D05) on contig 2374 (ABLG01002375) of the M. hapla genome (39) that has $75 \%$ nucleotide identity with Mi8D05. The longest ORF of the Mh8D05 (1,335 bp) encoded a deduced protein of 444 aa including a 23 -aa $\mathrm{N}$-terminal signal peptide as predicted by Signal $\mathrm{P}$ (6). Analysis of the 1,602-bp Mh8D05 genomic sequence identified one intron of $160 \mathrm{bp}$ that was upstream of the predicted ORF, but similar to Mi8D05, no intron sequences were identified within the Mh8D05 ORF. Comparison of amino acid sequences between Mi8D05 and Mh8D05 indicated that they have 55\% similarity (Fig. 1). SMART (49) analyses predicted two regions of 38 and 36 aa located between amino acids 53 to 90 and 159 to 194 that could form a coil-coil motif within Mi8D05. A similar coil-coil motif was predicted in Mh8D05 between 58 to 99 and 178 to 206 aa. No significant similarity in $8 D 05$ nucleotide or predicted peptide sequence was identified within the $H$. glycines or $C$. elegans genomes or through more comprehensive database searches.

The developmental expression of $8 D 05$ in five $M$. incognita life stages was assessed (Fig. 2) using qRT-PCR. Mi8D05 mRNA expression peaked in the parasitic J2 life stage (3 to 5 days postinfection) at about fourfold higher expression level than observed in preparasitic J2, J3, J4, and adult female life stages.

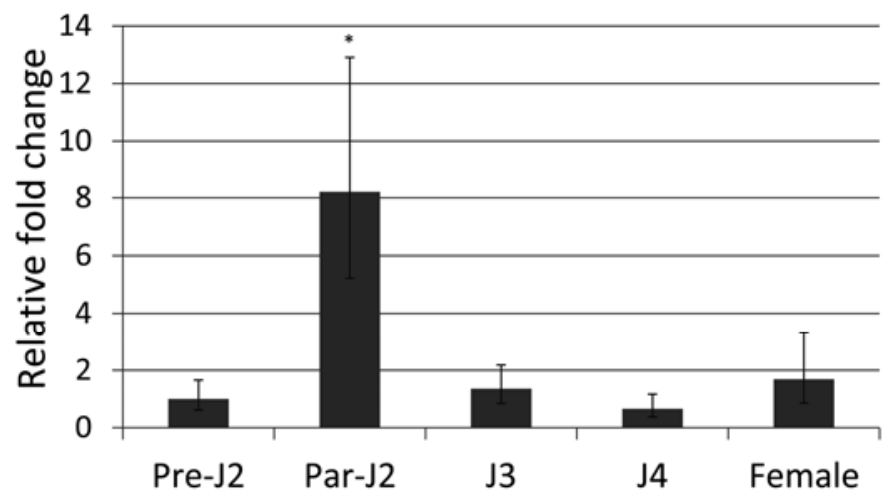

Fig. 2. Quantitative expression of Mi8D05 within developmental life stages of the root-knot nematode Meloidogyne incognita as determined by quantitative real-time reverse-transcription polymerase chain reaction. The relative foldchange values were calculated from three biological replicates using the $2^{-\Delta \Delta \mathrm{CT}}$ method (36) and represent changes in mRNA expression in nematode preparasitic J2 (Pre-J2), late parasitic J2 (Par-J2), J3, J4, and adult female life stages. The $M$. incognita actin gene (BE225475) was used as an internal control to normalize gene expression levels for all samples. Bars represent the standard error of the mean and significant $(P \leq 0.05)$ differences between values $(*)$ were derived by paired $t$ test. 
Purified Mi8D05 antiserum bound to secretory granules specifically within the subventral gland cells of preparasitic and parasitic $\mathrm{J} 2$ and their cytoplasmic extensions and expanded ampullae, which are located posterior to the pump chamber of the metacorpus (Fig. 3). No specific labeling with the rabbit preimmune serum was observed in any nematode specimens.

Overexpression and RNAi of Mi8D05 in Arabidopsis. Constitutive expression of Mi8D05 was confirmed in four homozygous transgenic lines of Arabidopsis using RT-PCR (data not shown). Expression of Mi8D05 with and without its native signal peptide significantly accelerated shoot growth and early flowering (Fig. 4A and B). Siliques also matured earlier in the Mi8D05 overexpression plants, but no visible differences in final plant heights or phenotypes were observed between Mi8D05 overexpression plants and wild-type Arabidopsis once all plants had reached maturity. Interestingly, no differences in root growth rate or phenotype were observed between Mi8D05 overexpression plants and wild-type Arabidopsis (Fig. 4C). An increase in susceptibility to infection by $M$. incognita was observed in all Mi8D05 overexpression lines compared with wild-type Arabidopsis although the values were not significantly $(P \leq 0.05)$ different (Fig. 4D).

The expression of the Mi8D05 hairpin dsRNA was confirmed in seven homozygous transgenic RNAi lines of Arabidopsis by RT-PCR of the PDK intron (data not shown) that separates the expressed complementary dsRNA arms when using the pHANNIBAL vector (57). No visible differences in root or shoot development and phenotype were observed between Mi8D05RNAi lines and wild-type Arabidopsis. Infection of all Mi8D05RNAi lines by $M$. incognita was reduced compared with wild-type Arabidopsis with six Mi8D05-RNAi lines having significantly $(P \leq 0.05)$ reduced infection rates (Fig. 5). Reduction in $M$. incognita infection among all Mi8D05-RNAi lines compared with wild-type plants ranged from 27 to $90 \%$, with four lines that reduced $M$. incognita infection between 73 to $90 \%$.

The interaction of Mi8D05 with plant host proteins. In the initial yeast two-hybrid screen that used Mi8D05 as bait and proteins expressed from a cDNA library constructed from unchallenged tomato roots (28) as prey, multiple interacting plant proteins in the major intrinsic protein (MIP) family (37) were isolated. The most highly represented Mi8D05-interacting MIP proteins included the plant aquaporins tonoplast intrinsic protein 2 (TIP2; AY731066) in truncated and full-length forms, tonoplast intrinsic protein 4 (TIP4; AB211518), and plasmalemma intrinsic protein 2 (PIP2; X73847, X73848). A subsequent yeast twohybrid screen using Mi8D05 as bait and prey proteins expressed from a cDNA library that was constructed from tomato roots at
7 days postinfection with $M$. incognita isolated multiple interactions with TIP2 (AY731066) almost exclusively (data not shown). Cotransformation assays in yeast between Mi8D05 and TIP2 confirmed the specificity of the interaction.

The expression of tip2 (AY731066) in tomato roots was monitored by qRT-PCR over several time points during infection by $M$. incognita and compared with tomato actin (U60481) expression to normalize the data. Expression levels of tip2 were each about onefold higher than baseline (actin) expression levels in both uninfected (check) tomato roots and tomato roots at 7 days postinfection by $M$. incognita, but tip2 expression was significantly reduced compared with uninfected roots of check plants by 14 and 24 days postinfection by M. incognita (Fig. 6).

\section{DISCUSSION}

The results of the functional analyses presented here suggest that the Mi8D05 parasitism gene produces a novel secreted effector protein that plays an important role in the parasitic interaction of root-knot nematodes with host plants. Mi8D05 peaks in expression in the parasitic $\mathrm{J} 2$ stage of $M$. incognita, the time when induction and early formation of giant-cells occurs (34). Relatively rapid induction in expression in parasitic $\mathrm{J} 2$ that have entered plant roots has been observed with several nematode parasitism genes to date (23-25), suggesting a developmental role in the early stages of the parasitic process. Immunodetection of the translated Mi8D05 protein specifically within the subventral gland cells of early stages of $M$. incognita indicates the potential for the effector to be secreted into host plant tissues (15,31). Only one database match of Mi8D05 was identified, a 1,602-bp genomic fragment (Mh8D05) on contig 2374 (ABLG01002375) of the M. hapla genome (39), indicating that 8D05 is a novel protein that may exist only within species of root-knot nematodes. The presence of a predicted secretion signal peptide, a relatively high similarity in protein size and sequence, and two conserved predicted coil-coil motifs suggest that Mi8D05 and Mh8D05 are homologs.

Constitutive expression of individual nematode parasitism genes in transformed Arabidopsis plants has served as a crude visual indicator of effector activity within host plant cells $(24,25$, 35,54-56). As in plants that express other nematode parasitism genes $(23-25,41)$, plants that overexpressed Mi8D05 were more susceptible to nematode infection (although not statistically significant with Mi8D05). Visible changes in shoot phenotype in Arabidopsis that overexpressed Mi8D05 have been observed with other parasitism genes (25,54-56), although the physiological basis of the accelerated shoot growth during Mi8D05 expression
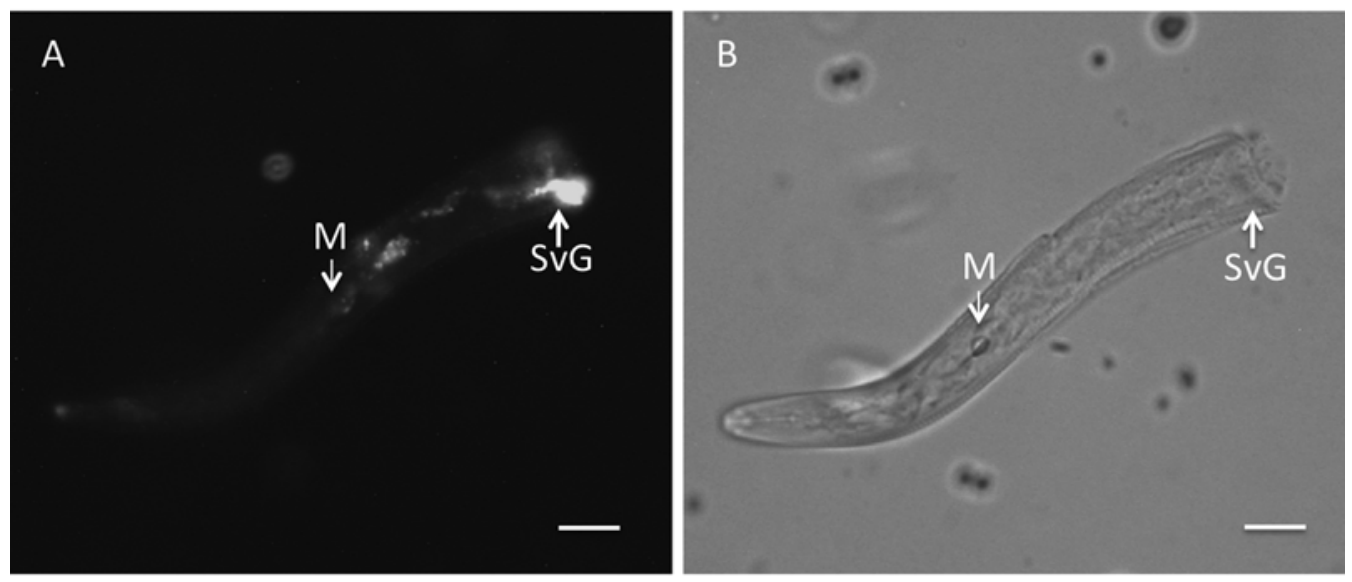

Fig. 3. Binding of antisera raised to predicted peptides within the Mi8D05 sequence within a parasitic J2 of Meloidogyne incognita that was excised from infected plant roots. A, Fluorescent (FITC) labeling indicates specific binding of the Mi8D05 antisera to proteins in granules within the two subventral esophageal gland cells ( $\mathrm{SvG}$ ) posterior to the nematode metacorpus (M). B, Light micrograph of the specimen shown in panel A. Scale bar represents $10 \mu \mathrm{m}$. 
remains unknown at present. It is interesting that effectors of root parasitic nematodes can have specific effects in plant shoot growth, confirming hypotheses that root-knot nematodes recruit a number of diverse plant developmental processes to form giantcells $(1,8,20,21)$. The specific acceleration of shoot growth (but not root growth) in Mi8D05 overexpression plants is just the opposite of the specific acceleration in only root growth observed in Arabidopsis plants that overexpress Mil6D10 (28). The Mi16D10 protein, however, was demonstrated to interact with members of the SCARECROW-like transcription factor family (28) that specifically regulate root cell growth and differentiation (43).

Very dramatic and significant reductions in infection rates of $M$. incognita were demonstrated in multiple lines of transgenic Mi8D05-RNAi Arabidopsis plants. Up to $90 \%$ reduction in gall formation was observed in Mi8D05-RNAi Arabidopsis plants, almost to the levels of reduction in $M$. incognita infection observed in Mil6D10-RNAi plants (27). Quantitative investigations of $8 D 05$ siRNA production in the different transgenic RNAi plant lines using high-throughput RNA sequencing technologies $(16,52)$ may shed light on the differential nematode infection rates observed among Mi8D05-RNAi lines. Quantitative assessment of PDK intron expression in RNAi constructs (not conducted here) could be used to provide a relative comparison of transgene ex-

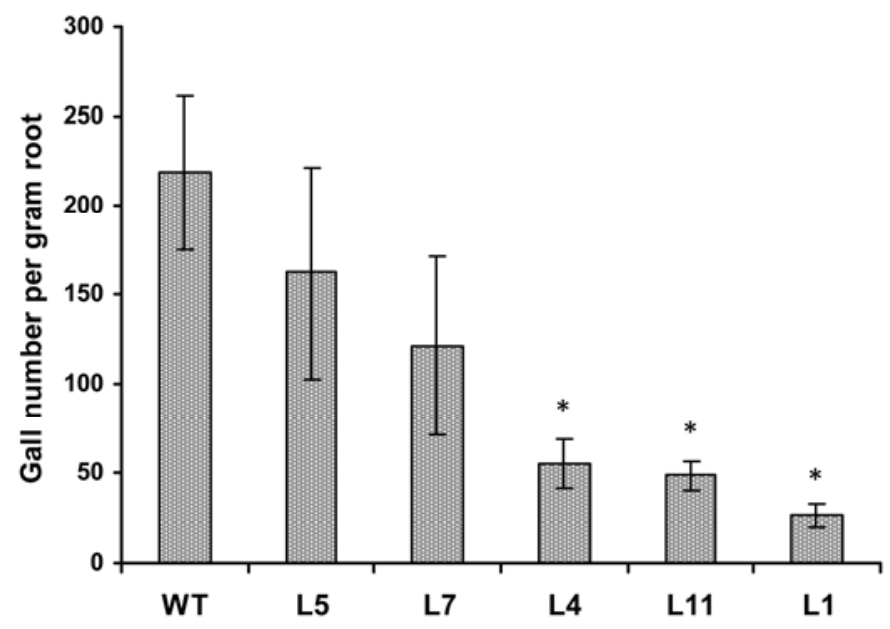

Fig. 5. Infection of plant roots (galls/gram of root) by Meloidogyne incognita decreased in all lines (L5, L7, L4, L11, and L1) of transgenic Arabidopsis thaliana that expressed double-stranded RNA (RNAi) complementary to the Mi8D05 parasitism gene coding sequence compared with wild-type (WT) Arabidopsis. Bars represent the standard error of the mean and significant $(P \leq$ 0.05 ) differences between values $(*)$ were derived by paired $t$ test.
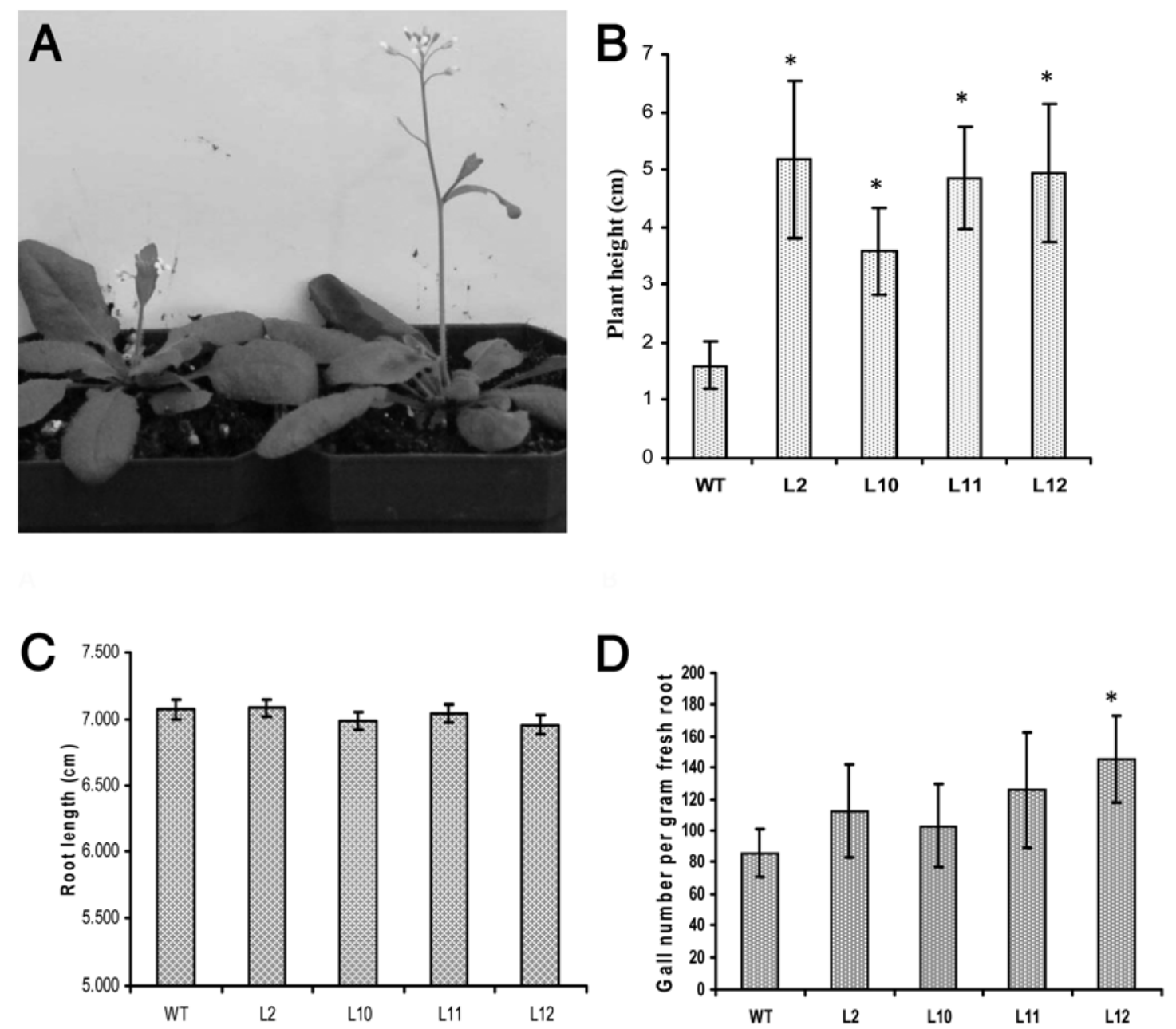

Fig. 4. Growth and nematode infection of transgenic Arabidopsis thaliana plants that constitutively expressed cDNA of the Mi8D05 parasitism gene of Meloidogyne incognita. A, Accelerated plant shoot development, early flowering, and $\mathbf{B}$, increased plant height were observed at 26 days after germination in transgenic Arabidopsis lines (L2, L10, L11, and L12) that constitutively expressed the Mi8D05 parasitism gene compared with wild-type (WT) Arabidopsis (Col-0). C, No significant differences in root growth were observed between WT and any transgenic Arabidopsis lines that constitutively expressed the Mi8D05 parasitism gene at any developmental stage. D, An increase (not statistically significant) in root infection rate (gall number) by $M$. incognita was observed in all transgenic Arabidopsis lines that constitutively expressed the Mi8D05 parasitism gene compared with WT. Bars represent the standard error of the mean and significant $(P \leq$ $0.05)$ differences between values $(*)$ were derived by paired $t$ test. 


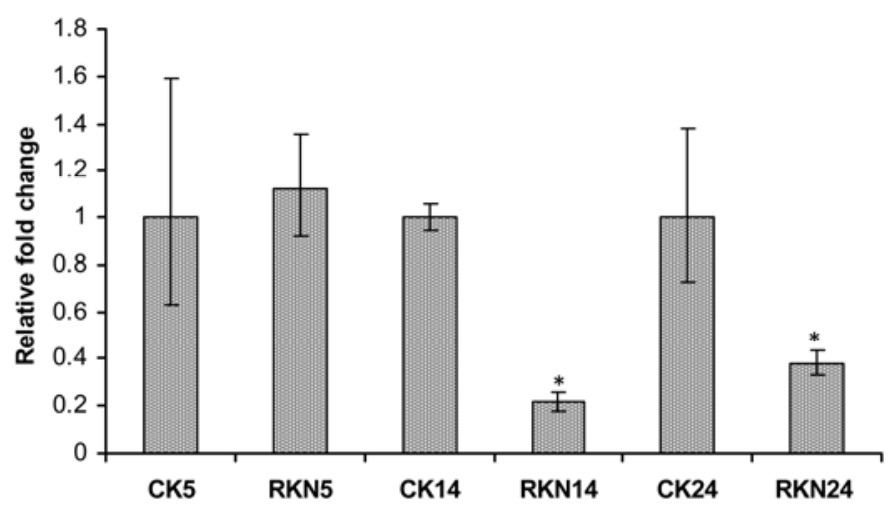

Fig. 6. Relative expression of the endogenous tomato tip2 (AY731066) gene that encodes the tonoplast intrinsic protein 2 (TIP2) aquaporin found to interact with the Mi8D05 effector protein of Meloidogyne incognita. Expression of tomato tip 2 was monitored in roots of noninfected check (CK) roots and tomato roots at 5, 14, and 24 days postinfection with the root-knot nematode (RKN), M. incognita. The relative fold-change values were calculated using the $2^{-\Delta \Delta C T}$ method (36) and represent differences in mRNA expression levels between infected and noninfected roots at each time point. The tomato actin gene (U60481) was used as an internal control to normalize gene expression levels for all samples. Bars represent the standard error of the mean and significant $(P \leq 0.05)$ differences between values $(*)$ were derived by paired $t$ test.

pression levels among lines, but assay of the siRNA levels would provide the most accurate measure of processed bioactive RNA molecules to relate to nematode infection levels. Essentially every Mi8D05-RNAi line tested had significant reductions in $M$. incognita infection rates, however, indicating that the Mi8D05 parasitism gene (and its encoded effector) plays a critical role in the parasitic process of the root-knot nematode.

The specific interaction of the Mi8D05 protein with plant aquaporins (37), primarily tonoplast intrinsic protein 2 (TIP2) from tomato roots (AY731066) that had been infected with M. incognita, suggests a potential role for the 8D05 effector protein in regulating water and solute transport in giant-cells. Interestingly, one of the first root-knot nematode-inducible plant promoters identified (40) increased specific expression of the $T o b R b 7$ aquaporin gene in giant-cells, and RB7 aquaporins are now considered members of the TIP family of plant proteins $(47,53)$. Given the similarities in metabolic upregulation within both syncytia formed by cyst nematodes and giant-cells formed by root-knot nematodes, high solute concentrations $(7,26)$ that lead to increased turgor pressure in feeding cells would require careful regulation to maintain feeding cell integrity. This potential regulation may occur at the protein interaction level in the early stages of parasitism when transcripts encoding both the Mi8D05 effector and plant TIP2 proteins are most highly expressed and giant-cell formation has commenced. By 14 days postinfection with root-knot nematodes, the giant-cells are fully formed (34) and Mi8D05 and tip2 expression have been minimized. Subsequent high-resolution localization experiments of Mi8D05 and TIP2 interactions within host plant cells combined with functional data using tip2 mutant plants, tip2 overexpression, and physiological indicators of cellular water and solute transport (37) will refine our understanding of the functional role of the Mi8D05 effector in parasitism.

\section{ACKNOWLEDGMENTS}

This research was supported by the U.S.-Israel Binational Agricultural Research and Development (BARD) Grant US-4158-08 (to E. L. Davis) and by the United Soybean Board Project 2280 (to E. L. Davis and T. J. Baum).

\section{LITERATURE CITED}

1. Abad, P., Favery, B., Rosso, M. N., and Castagnone-Sereno, P. 2003. Root-knot nematode parasitism and host response: Molecular basis of a sophisticated interaction. Mol. Plant Pathol. 4:217-224.

2. Abad, P., Gouzy, J., Aury, J. M., Castagnone-Sereno, P., Danchin, E. G. J., Deleury, E., Perfus-Barbeoch, L., Anthouard, V., Artiguenave, F., Blok, V. C., Caillaud, M. C., Coutinho, P. M., Dasilva, C., De Luca, F., Deau, F., Esquibet, M., Flutre, T., Goldstone, J. V., Hamamouch, N., Hewezi, T., Jaillon, O., Jubin, C., Leonetti, P., Magliano, M., Maier, T. R., Markov, G. V., McVeigh, P., Pesole, G., Poulain, J., Robinson-Rechavi, M., Sallet, E., Segurens, B., Steinbach, D., Tytgat, T., Ugarte, E., van Ghelder, C., Veronico, P., Baum, T. J., Blaxter, M., Bleve-Zacheo, T., Davis, E. L., Ewbank, J. J., Favery, B., Grenier, E., Henrissat, B., Jones, J. T., Laudet, V., Maule, A. G., Quesneville, H., Rosso, M. N., Schiex, T., Smant, G., Weissenbach, J., and Wincker, P. 2008. Genome sequence of the metazoan plant-parasitic nematode Meloidogyne incognita. Nat. Biotechnol. 26:909-915.

3. Bakhetia, M. B., Urwin, P. E., and Atkinson, H. J. 2007. qPCR analysis and RNAi define pharyngeal gland cell-expressed genes of Heterodera glycines required for initial interactions with the host. Mol. PlantMicrobe Interact. 20:306-312.

4. Barcala, M., García, A., Cabrera, J., Casson, S., Lindsey, K., Favery, B., Garcia-Casado, G., Solano, R., Fenoll, C., and Escobar, C. 2010. Early transcriptomic events in microdissected Arabidopsis nematode-induced giant-cells. Plant J. 61:698-712.

5. Barker, K. R. 1998. Introduction and synopsis of advancements in nematology. Pages 1-20 in: Plant Nematode Interactions. K. R. Barker, G. A. Pederson, and G. L. Windham, eds. American Society of Agronomy, Crop Science Society of America, and Soil Science Society of America, Madison, WI.

6. Bendtsen, J. D., Nielsen, H., von Heijne, G., and Brunak, S. 2004. Improved prediction of signal peptides: SignalP 3.0. J. Mol. Biol. 340:783-795.

7. Betka, M., Grundler, F. M. W., and Wyss, U. 1991. Influence of changes in the nurse cell system (syncytium) on sex determination and development of the cyst nematode Heterodera schactii: Single amino acids. Phytopathology 81:75-79.

8. Bird, D. M. 1996. Manipulation of host gene expression by root-knot nematodes. J. Parasitol. 82:881-888.

9. Chen, P. Y., Wang, C. K., Soong, S. C., and To, K. Y. 2003. Complete sequence of the binary vector pBI121 and its application in cloning T-DNA insertion from transgenic plants. Mol. Breed. 11:287-293.

10. Chen, Q., Rehman, S., Smant, G., and Jones, J. T. 2005. Functional analysis of pathogenicity proteins of the potato cyst nematode Globodera rostochiensis using RNAi. Mol. Plant-Microbe Interact. 18:621-625.

11. Chitwood, D. J. 2003. Research on plant-parasitic nematode biology conducted by the United States Department of Agriculture-Agricultural Research Service. Pest Management Sci. 59:748-753.

12. Clough, S. J., and Bent, A. F. 1998. Floral dip: A simplified method for Agrobacterium-mediated transformation of Arabidopsis thaliana. Plant $\mathrm{J}$. 16:735-743.

13. Davis, E. L., Hussey, R. S., and Baum, T. J. 2009. Parasitism genes: What they reveal about parasitism. Pages 15-44 in: Plant Cell Monographs: Cell Biology of Plant Nematode Interactions. R. H. Berg and C. G. Taylor, eds. Springer, Heidelberg.

14. Davis, E. L., Hussey, R. S., Baum, T. J., Bakker, J., Schots, A., Rosso, M. N., and Abad, P. 2000. Nematode parasitism genes. Annu. Rev. Phytopathol. 38:365-396.

15. Davis, E. L., Hussey, R. S., Mitchum, M. G., and Baum, T. J. 2008. Parasitism proteins in nematode-plant interactions. Curr. Opin. Plant Biol. 11:360-366.

16. De Paoli, E., Dorantes-Acosta, A., Zhai, J., Accerbi, M., Jeong, D. H., Park, S., Meyers, B. C., Jorgensen, R. A., and Green, P. J. 2009. Distinct extremely abundant siRNAs associated with cosuppression in petunia. RNA 15:1965-1070.

17. Ding, X., Shields, J., Allen, R., and Hussey, R. S. 1998. A secretory cellulose-binding protein cDNA cloned from the root-knot nematode (Meloidogyne incognita). Mol. Plant-Microbe Interact. 11:952-959.

18. Doyle, E. A., and Lambert, K. N. 2003. Meloidogyne javanica chorismate mutase 1 alters plant cell development. Mol. Plant-Microbe Interact. 16:123-131.

19. Fire, A., Xu, S. Q., Montgomery, M. K., Kostas, S. A., Driver, S. E., and Mello, C. C. 1998. Potent and specific genetic interference by double stranded RNA in Caenorhabditis elegans. Nature 391:806-811.

20. Gheysen, G., and Mitchum, M. G. 2009. Molecular insights in the susceptible plant response to nematode infection. Pages 45-82 in: Plant Cell Monographs: Cell Biology of Plant Nematode Interactions. R. H. Berg and C. G. Taylor, eds. Springer, Heidelberg.

21. Gheysen, G., and Mitchum, M. G. 2011. How nematodes manipulate plant development pathways for infection. Curr. Opin. Plant Biol. 14:1-7.

22. Gleave, A. P. 1992. A versatile binary vector system with a T-DNA organizational-structure conducive to efficient integration of cloned DNA into the plant genome. Plant Mol. Biol. 20:1203-1207.

23. Hamamouch, N., Li, C., Hewezi, T., Baum, T. J., Mitchum, M. G., Hussey, R. S., Vodkin, L. O., and Davis, E. L. 2012. The interaction of the 
novel 30C02 cyst nematode effector protein with a plant beta-1,3 endoglucanase may suppress host defence to promote parasitism. J. Exp. Bot. 63:3683-3695.

24. Hewezi, T., Howe, P. J., Maier, T. R., Hussey, R. S., Mitchum, M. G., Davis, E. L., and Baum, T. J. 2008. Cellulose binding protein from the parasitic nematode Heterodera schachtii interacts with Arabidopsis pectin methylesterase: Cooperative cell wall modification during parasitism. Plant Cell 20:3080-3093.

25. Hewezi, T., Howe, P. J., Maier, T. R., Hussey, R. S., Mitchum, M. G., Davis, E. L., and Baum, T. J. 2010. Arabidopsis spermidine synthase is targeted by an effector protein of the cyst nematode Heterodera schachtii. Plant Physiol.152:968-984.

26. Hofmann, J., and Grundler, F. M. W. 2007. How do nematodes get their sweets? Solute supply to sedentary plant-parasitic nematodes. Nematology 9:451-458.

27. Huang, G., Allen, R., Davis, E. L., Baum, T. J., and Hussey, R. S. 2006. Engineering broad root-knot resistance in transgenic plants by RNAi silencing of a conserved and essential root-knot nematode parasitism gene. Proc. Natl. Acad. Sci. USA 103:14302-14306.

28. Huang, G., Dong, R., Allen, R., Davis, E. L., Baum, T. J., and Hussey, R. S. 2006. A root-knot nematode secretory peptide functions as a ligand for a plant transcription factor. Mol. Plant-Microbe Interact. 19:463-470.

29. Huang, G., Dong, R., Maier, T., Allen, R., Davis, E. L., Baum, T. J., and Hussey, R. S. 2004. Use of solid-phase subtractive hybridization for the identification of parasitism gene candidates from the root-knot nematode Meloidogyne incognita. Mol. Plant Pathol. 5:217-222.

30. Huang, G., Gao, B., Maier, T., Allen, R., Davis, E. L., Baum, T. J., and Hussey, R. S. 2003. A profile of putative parasitism genes expressed in the esophageal gland cells of the root-knot nematode Meloidogyne incognita. Mol. Plant-Microbe Interact. 16:376-381.

31. Hussey, R. S. 1989. Disease-inducing secretions of plant-parasitic nematodes. Annu. Rev. Phytopathol. 27:123-141.

32. Hussey, R. S., and Barker, K. R. 1973. A comparison of methods of collecting inocula of Meloidogyne spp. Plant Dis. Rep. 57:1025-1028.

33. Hussey, R. S., and Grundler, F. M. W. 1998. Nematode parasitism of plants. Pages 213-243 in: The Physiology and Biochemistry of FreeLiving and Plant Parasitic Nematodes. R. N. Perry and D. J. Wright, eds. CABI, Wallingford, UK.

34. Jones, M. G. K. 1981. Host-cell responses to endo-parasitic nematode attack-Structure and function of giant-cells and syncytia. Ann. Appl. Biol. 97:353-372.

35. Lee, C., Chronis, D., Kenning, C., Peret, B., Hewezi, T., Davis, E. L., Baum, T. J., Hussey, R. S., Bennett, M., and Mitchum, M. G. 2011. The novel cyst nematode effector protein 19C07 interacts with the Arabidopsis auxin influx transporter LAX3 to control feeding site development. Plant Physiol. 155:866-880.

36. Livak, K. J., and Schmittgen, T. D. 2001. Analysis of relative gene expression data using real-time quantitative PCR and the 2(T)(-Delta Delta C) method. Methods 25:402-408.

37. Maurel, P., Verdoucq, L., Luu, D. T., and Santoni, V. 2008. Plant aquaporins: Membrane channels with multiple integrated functions. Annu. Rev. Plant Biol. 59:595-624.

38. Murashige, T., and Skoog, F. 1962. A revised medium for rapid growth and bioassays with tobacco tissue cultures. Physiol. Plant 15:473-497.

39. Opperman, C. H., Bird, D. M., Williamson, V. M., Rokhsar, D. S., Burke, M., Cohn, J., Cromer, J., Diener, S., Gajan, J., Graham, S., Houfek, T. D., Liu, Q., Mitros, T., Schaff, J., Schaffer, R., Scholl, E., Sosinski, B. R., Thomas, V. P., and Windham, E. 2008. Sequence and genetic map of Meloidogyne hapla: A compact nematode genome for plant parasitism. Proc. Natl. Acad. Sci. USA 105:14802-14807.

40. Opperman, C. H., Taylor, C. G., and Conkling, M. A. 1994. Root-knot nematode directed expression of a plant root-specific gene. Science 263: 221-223.

41. Patel, N., Hamamouch, N., Li, C., Hewezi, T., Hussey, R. S., Baum, T. J.,
Mitchum, M. G., and Davis, E. L. 2010. A nematode effector protein similar to annexins in host plants. J. Exp. Bot. 61:235-248.

42. Patel, N., Hamamouch, N., Li, C., Hussey, R., Mitchum, M., Baum, T., Wang, X., and Davis, E. L. 2008. Similarity and functional analyses of expressed parasitism genes in Heterodera schachtii and Heterodera glycines. J. Nematol. 40:299-310.

43. Pysh, L. D., Wysocka-Diller, J. W., Camilleri, C., Bouchez, D., and Benfey, P. N. 1999. The GRAS gene family in Arabidopsis: Sequence characterization and basic expression analysis of the SCARECROW-LIKE genes. Plant J. 18:111-119.

44. Rehman, S., Postma, W., Tytgat, T., Prins, P., Qin, L., Overmars, H., Vossen, J., Spiridon, L. N., Petrescu, A. J., Goverse, A., Bakker, J., and Smant, G. 2009. A secreted SPRY domain-containing protein (SPRYSEC) from the plant-parasitic nematode Globodera rostochiensis interacts with a CC-NB-LRR protein from a susceptible tomato. Mol. Plant-Microbe Interact. 22:330-340.

45. Rosso, M. N., Hussey, R. S., Davis, E. L., Smant, G., Baum, T. J., Abad, P., and Mitchum, M. G. 2012. Nematode effector proteins: Targets and functions in plant parasitism. Pages 329-356 in: Effectors in Plant-Microbe Interactions. F. Martin and S. Kamoun, eds. Wiley-Blackwell, New York.

46. Rosso, M. N., Jones, J. T., and Abad, P. 2009. RNAi and functional genomics in plant parasitic nematodes. Annu. Rev. Phytopathol. 47:207-232.

47. Sarda, X., Tousch, D., Ferrare, K., Cellier, F., Alcon, C., Dupuis, J. M., Casse, F., and Lamaze, T. 1999. Characterization of closely-related deltaTIP genes encoding aquaporins which are differentially expressed in sunflower roots upon water deprivation through exposure to air. Plant Mol. Biol. 40:179-191.

48. Sasser, J. N. 1980. Root-knot nematodes: A global menace to crop production. Plant Dis. 64:36-41.

49. Schultz, J., Milpetz, F., Bork, P., and Ponting, C. P. 1998. SMART, a simple modular architecture research tool: Identification of signaling domains. Proc. Natl. Acad. Sci. USA 95:5857-5864.

50. Sijmons, P. C., Grundler, F. M. W., von Mende, N., Burrows, P. R., and Wyss, U. 1991. Arabidopsis thaliana as a new model for plant-parasitic nematodes. Plant J. 1:245-254.

51. Sindhu, A. S., Maier, T. R., Mitchum, M. G., Hussey, R. S., Davis, E. L., and Baum, T. J. 2009. Effective and specific in planta RNAi in cyst nematodes: Expression interference of four parasitism genes reduces parasitic success. J. Exp. Bot. 60:315-324.

52. Tuteja, J., Zabala, G., Varala, K., Hudson, M., and Vodkin, L. 2009. Endogenous, tissue specific short interfering RNAs silence the chalcone synthase gene family in Glycine max seed coats. Plant Cell 21:3063-3077.

53. Vaughan, S. P., James, D. J., Lindsey, K., and Massiah, A. J. 2006. Characterization of FaRB7, a near root-specific gene from strawberry (Fragaria $\times$ ananassa Duch.) and promoter activity analysis in homologous and heterologous hosts. J. Exp. Bot. 57:3901-3910.

54. Wang, J., Lee, C., Replogle, A., Joshi, S., Korkin, D., Hussey, R. S., Baum, T. J., Davis, E. L., Wang, X., and Mitchum, M. G. 2010. Dual roles for the variable domain in protein trafficking and host-specific recognition of Heterodera glycines CLE effector proteins. New Phytol. 187:10031017.

55. Wang, J., Replogle, A., Hussey, R. S., Baum, T. J., Wang, X., Davis, E. L., and Mitchum, M. G. 2010. Identification of potential host plant mimics of CLV3/ESR (CLE)-like peptides from the plant parasitic nematode Heterodera schachtii. Mol. Plant Pathol. 12:177-186.

56. Wang, X., Mitchum, M. G., Gao, B., Li, C., Diab, H., Baum, T. J., Hussey, R. S., and Davis, E. L. 2005. A parasitism gene from a plant parasitic nematode with function similar to CLAVATA3/ESR (CLE) of Arabidopsis thaliana. Mol. Plant Pathol. 6:187-191.

57. Wesley, S. V., Helliwell, C. A., Smith, N. A., Wang, M. B., Rouse, D. T., Liu, Q., Gooding, P. S., Singh, S. P., Abbott, D., Stoutjesdijk, P. A., Robinson, S. P., Gleave, A. P., Green, A. G., and Waterhouse, P. M. 2001. Construct design for efficient, effective and high-throughput gene silencing in plants. Plant J. 27:581-590. 